\section{ENHANCING HYDROPHILICITY OF POLYSULFONE MEMBRANE SURFACE BY UV IRRADIATION OF DIFFERENT WAVELENGTHS AND BY PEG GRAFTING}

Soraya Ruangdita,b, Suksawat Sirijarukula,b*, Thawat Chittrakarna,b, Chaiporn Kaew-onc

aFaculty of Science, Division of Physical Science, Faculty of Science, Prince of Songkla University, Hat Yai, Songkhla, Thailand, 90112 ${ }^{b}$ Center of Excellence in Membrane Science and Technology, Prince of Songkla University, Songkhla, Thailand, 90112

cFaculty of Science and Technology, Nakhon Si Thammarat Rajabhat University, Nakhon Si Thammarat, Thailand, 80280
Article history

Received

8 December 2020

Received in revised form

5 May 2021

Accepted

23 May 2021

Published online

20 June 2021

*Corresponding author suksawat.s@psu.ac.th

\section{Graphical abstract}

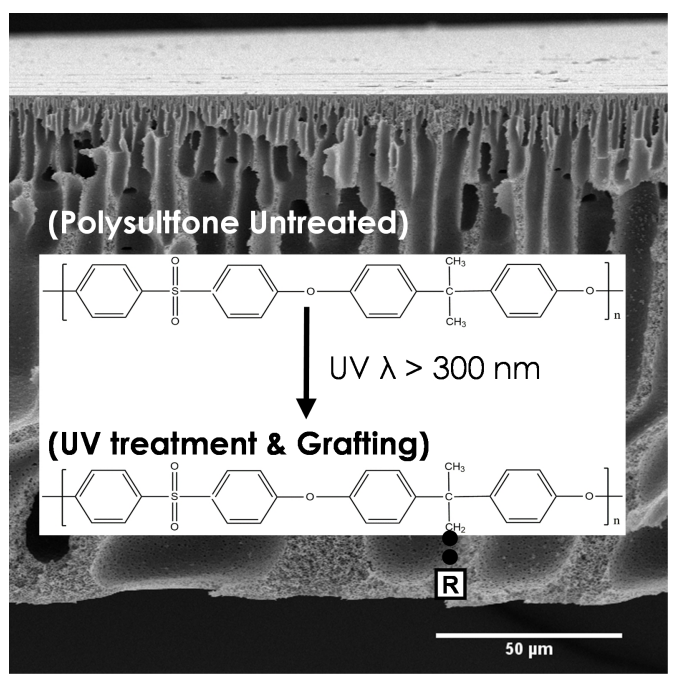

\section{Abstract}

Polysulfone polymer (PSF) membrane has disadvantages due to its hydrophobicity, which may cause fouling and reduce separation performance. Therefore, this study aimed to enhance the hydrophilicity of PSF membranes by using irradiation at different ultraviolet (UV) wavelengths, followed by Poly(ethylene glycol) (PEG) grafting on the PSF surfaces. The hydrophilicity of the treated membrane surfaces was examined by measuring water contact angle (WCA), surface energy (SE), surface morphology, functional groups, salt rejection, and water flux in a filtration instrument. The results show that with long UV treatment for up to $72 \mathrm{~h}$, the $312 \mathrm{~nm}$ wavelength gave lesser WCA than treatment at $254 \mathrm{~nm}$. The treated PSF membrane irradiated at $312 \mathrm{~nm}$ for $72 \mathrm{~h}$, followed by PEG grafting, was effectively improved and retained increased hydrophilicity for up to thirty days.

Keywords: UV treatment, PEG-grafting, Surface modification, hydrophilicity, polar component

\subsection{INTRODUCTION}

Membrane technology is pervasive in the industry. Polysulfone (PSF) has been widely used as a polymer in the commercial production of microfiltration and ultrafiltration membranes, due to several advantages, such as good mechanical, chemical, and thermal properties, and easy film-forming [1, 2]. However, PSF membranes tend to have severe fouling during filtration due to natural hydrophobicity, low surface energy, and non-ionic character [3]. The membrane surface properties play a key role in the interactions with atoms or molecules or other active particles. Many polymers that have been used in membranes are hydrophobic with a low surface energy, such as poly(ethylene terephthalate) $(24.2 \mathrm{mN} / \mathrm{m})$, poly(propylene) $(29.5 \mathrm{mN} / \mathrm{m})$, and poly(vinylidene fluoride) $(42-47 \mathrm{mN} / \mathrm{m})[4,5]$. If the membrane surface is hydrophilic with a high surface energy, this reduces fouling due to electrostatic repulsion of other molecules from the membrane surface [6]. Several methods have been used in many studies to improve membrane surface energy, such as coating with a hydrophilic polymer for increased hydrophilicity of 
the PSF membrane [7], or by blending in hydrophilic or organic materials or some minerals $[8,9]$. Physical treatment with plasma is a popular technique due to its high efficiency. However, the weakness of this technique is that it still requires a low-pressure system for processing [10, 11]. Ultraviolet (UV) irradiation is another technique that is in widespread use to improve the surface properties, because it can work at atmospheric pressure and can change membrane surface properties without adverse influence on the bulk properties [12]. UV light can generate free radicals on the membrane surfaces by cutting chemical bonds of atoms or molecules. A PSF membrane surface irradiated with UV followed by Poly(ethylene glycol)(PEG) grafting was found to have enhanced charge density and pure water flux [13]. Many studies have used PEG as a membrane component to solve the problem of free radical disintegration on the membrane surfaces, which causes reversal back to hydrophobicity, because PEG is hydrophilic with flexible chains. However, it is difficult to put PEG on the membrane surfaces due to its poor mechanical and thermal properties. So, PEG grafting with UV light assistance has been studied to address these problems. The high-energy UV irradiated PSF membrane surfaces can struggle for balance between crosslinking and chain scission, causing a decreased water flux [14]. The membrane grafted with UV assistance was found to have improved antifouling performance [15]. The mechanism of polymer membrane improvement can be described as follows. In the first step, high-energy UV light generates free radical polymers. After that, the radical species will interact with other functional materials in the second step. The further interactions in the second step and the interactions between particles in the second step along with other functional materials continues until saturation [16].

The natural UV-rays have a wide wavelengths range (200-400 nm) and each wavelength has a different quantum energy [17]. So, irradiation by different UV wavelengths for different treatment times can provide different surface properties. Such factors may affect PEG grafting on the membrane surface with UV assistance. So, this investigation studied the effects of different UV-ray wavelengths and treatment times for improving hydrophilicity properties of PSF membranes by grafting with PEG, and studied the permanence or longevity of the hydrophilicity improvement.

\subsection{METHODOLOGY}

Polysulfone (PSF) Udel P-1700 as pellets was supplied by Solvay (China). Polyvinylpyrrolidone (PVP, K30) and Poly (ethylene glycol) (MW 8,000) (PEG) were purchased from Sigma-Aldrich, while N-Methyl-2Pyrrolidone (NMP) was supplied by $\mathrm{ACl}$ Lab-scan (Thailand). Sodium chloride (NaCl) was purchased from Ajax Finechem.
The dope solution for this work was prepared by mixing $17.5 \mathrm{wt} \%$ PSF, $0.5 \mathrm{wt \%}$ PVP and $82 \mathrm{wt} \%$ NMP. The PSF pellets were dried at $80{ }^{\circ} \mathrm{C}$ for $24 \mathrm{~h}$ in a vacuum oven (BINDER, VD53) before use. To prepare the dope solution, PVP and NMP were mixed in a beaker before stirred for 10 min with a magnetic stirrer. Then, PSF pellets were added into the solution under vigorous stirring for $24 \mathrm{~h}$. After that, the solution was ultra-sonicated in an ultrasonic cleaner (GT SONIC, VGT-1620T) for 30 min to remove any bubbles. Subsequently, the free bubble dope solution was cast on a smooth clear glass plate followed by instantaneous immersion in reverse osmosis (RO) water coagulation bath at room temperature $\left(23^{\circ} \mathrm{C}\right)$ for wet phase inversion, to form a wet thin membrane. After peeling off from the glass plate, the membrane was placed in a second RO water bath and was soaked for $24 \mathrm{~h}$ to remove the solvent. Afterwards, the membrane was desiccated in ambient conditions for $24 \mathrm{~h}$ and dried in a vacuum oven at $70^{\circ} \mathrm{C}$ for $24 \mathrm{~h}$ before use.

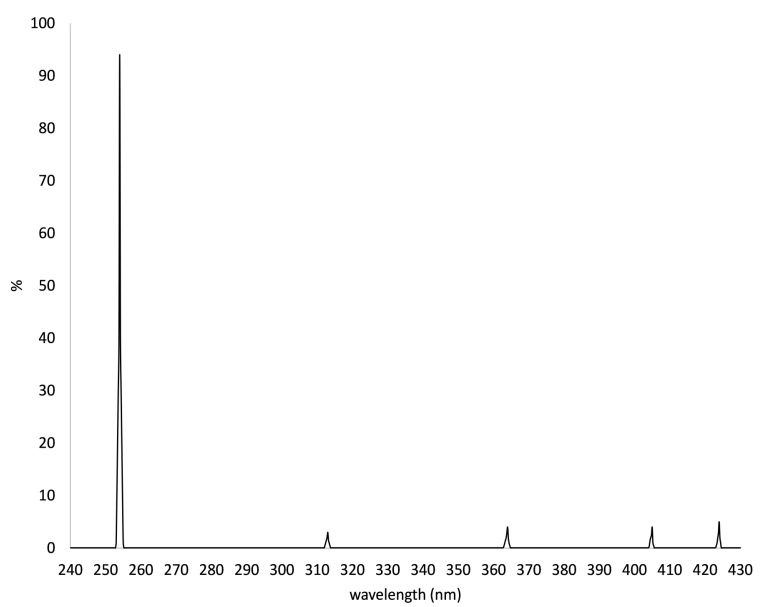

(A)

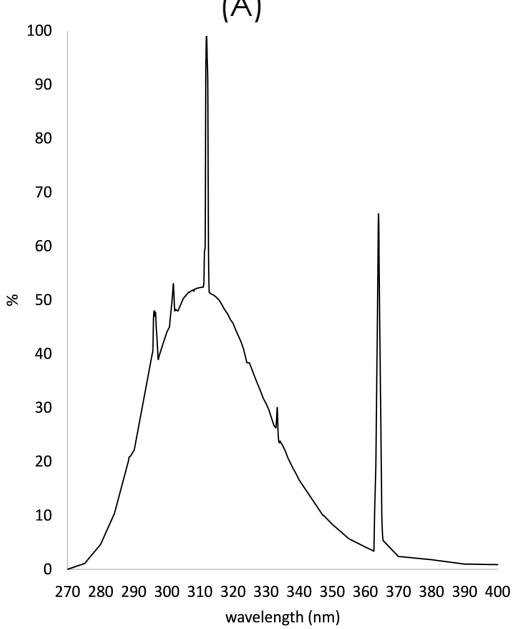

(B)

Figure 1 The spectra of UV sources for (A) $254 \mathrm{~nm}$, and (B) $312 \mathrm{~nm}$ nominal wavelengths 
The optimized membrane surface was irradiated by UV radiation in the ambient atmosphere $\left(25 \pm 2{ }^{\circ} \mathrm{C}\right.$ and $60-65 \%$ relative humidity, measured by Traceable Digital Thermohygrometer, Cole-Palmer (Thailand)). The sample membranes were exposed to UV source $(15 \mathrm{~W}-254 \mathrm{~nm}$ or $15 \mathrm{~W}-312 \mathrm{~nm}$, Vilber Lourmal, VI-215. MC (France)) for different conditions shown in Table 1 while the distance between the membrane sample and the UV source was kept fixed at $20 \mathrm{~cm}$. The spectrum of UV source for this experiment was characterized by using a laser power meter, Coherent Inc.; GES-UM2, shown in Figure $1 \mathrm{~A}$ and 1B [18]. After the UV treatment, the membrane was immersed in PEG solution (1.0 wt\%) for $3 \mathrm{~h}$. After that, the treated membrane was soaked in RO water for $24 \mathrm{~h}$ before drying in ambient air at room temperature for $12 \mathrm{~h}$ before testing. After treatment process was complete, the first set of the treated membrane was verified by measuring WCA and the other set of dry membranes was retained in ambient air at temperature of $23-25^{\circ} \mathrm{C}$ and relative humidity of $66-68 \%$ for 30 days before testing

Table 1 The conditions of UV treatment membrane

\begin{tabular}{lllllll}
\hline \multicolumn{2}{c}{ Condition } & $\mathbf{5 h}$ & $\mathbf{1 0} \mathbf{h}$ & $\mathbf{2 4} \mathbf{h}$ & $\mathbf{4 8} \mathbf{h}$ & $\mathbf{7 2} \mathbf{h}$ \\
\hline $\mathbf{U V} \mathbf{2 5 4} \mathbf{n m}$ & NO PEG & A5 & A10 & A24 & A48 & A72 \\
& PEG & B5 & B10 & B24 & B48 & B72 \\
UV $\mathbf{3 1 2} \mathbf{n m}$ & NO PEG & C5 & C10 & C24 & C48 & C72 \\
& PEG & D5 & D10 & D24 & D48 & D72 \\
\hline
\end{tabular}

The morphology of the treated membrane was investigated on top side, bottom side and in a crosssection by using a Scanning Electron Microscope (SEM, JSM-5800 LV). The hydrophilicity of the treated membrane was examined by measuring the water contact angle (WCA) and the surface energy (SE). The measurement of contact angle was done with three types of liquid: water, Formamide and Ethylene glycol with known $\gamma^{p}$ (polar component) and $\gamma^{d}$ (dispersive component). The SE was calculated with Equation (1) [19, 20].

$$
\mathrm{\gamma}_{L V}(1+\cos \theta)=2\left(\mathrm{\gamma}_{L}^{d} \cdot \mathrm{\gamma}_{S}^{d}\right)^{1 / 2}+2\left(\mathrm{\gamma}_{L}^{p} \cdot \mathrm{\gamma}_{S}^{P}\right)^{1 / 2}
$$

The functional groups on the PSF membrane surface were assessed by using attenuated total reflection Fourier transform infrared (ATR-FTIR) spectroscopy (Bruker, Hyperion 3000).

Before membrane testing, the membrane was immersed in water for 1 hour. After that, the reverse osmosis water was forced through each treated membrane in a cross-flow process at $0.1 \mathrm{MPa}$ to characterize the water flux $\left(\mathrm{L} \mathrm{m}^{-2} \mathrm{~h}^{-1}\right)$ using Equation (2) $[9,21]$.

$$
\text { Flux }=\frac{V}{A \times t}
$$

Here $\mathrm{V}$ is the volume of the filtrate $\left(\mathrm{L}\right.$ or $\left.\mathrm{dm}^{3}\right), \mathrm{A}$ is the practicable area of the membrane $\left(\mathrm{m}^{2}\right)$ and $t$ is the testing time (h).
The rejection rate was also used to assess the treated membrane properties after 30 min of filtration. The conductivities of permeate and feed solution were measured by using Eutech Instruments, Syberscan PC300 (Singapore). The rejection ratio (R) was calculated according to Equation (3).

$$
R(\%)=1-\frac{c_{p}}{c_{f}} \times 100 \%
$$

Here $\mathrm{C}_{f}$ and $\mathrm{C}_{p}$ are the Sodium chloride ( $\mathrm{NaCl}$ ) concentrations of permeate and feed solution (1 molar), respectively.

\subsection{RESULTS AND DISCUSSION}

The hydrophilicity properties of the variously treated PSF membranes were examined by measuring WCA and SE, with results shown in Figure 2. For the treatment times from 0 to $10 \mathrm{~h}$, WCA after treatment at UV wavelength $254 \mathrm{~nm}$ (UV254) was lower than after treatment at $312 \mathrm{~nm}$ (UV312), as shown in Figure 2(A). This means that for treatment times shorter than $10 \mathrm{~h}$, the hydrophilicity with UV254 was better than with UV312. However, for treatment times exceeding $10 \mathrm{~h}$, the WCA with UV312 was less than that with UV254: for comparatively long treatments up to $72 \mathrm{~h}$, the hydrophilicity with UV312 was better than with UV254, as shown in Figure 2(A).

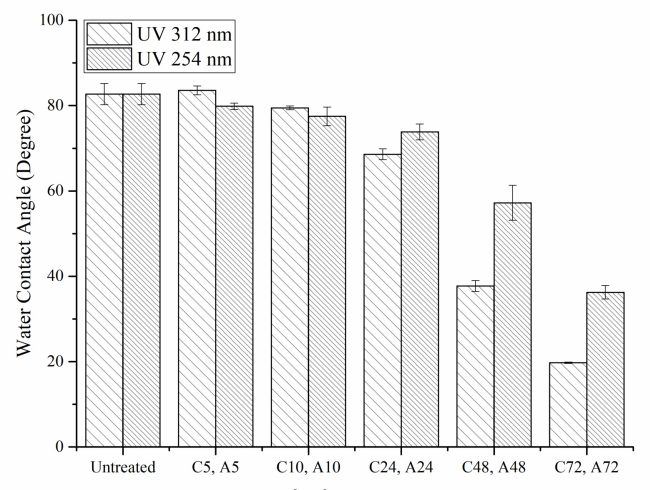

(A)

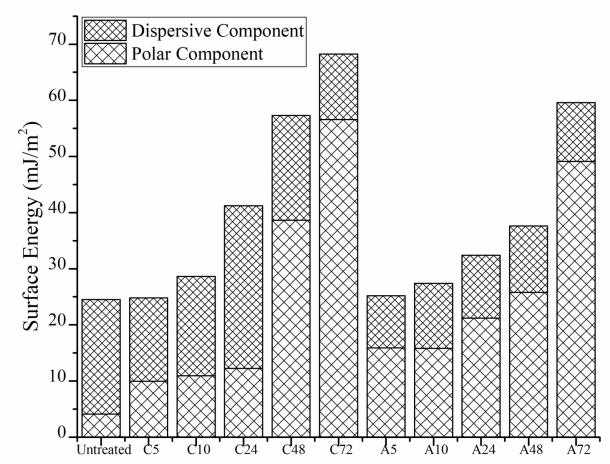

(B)

Figure 2 The water contact angles (A), and surface energies (B) of membranes treated with UV254 and UV312 for various treatment times (without PEG grafting) 


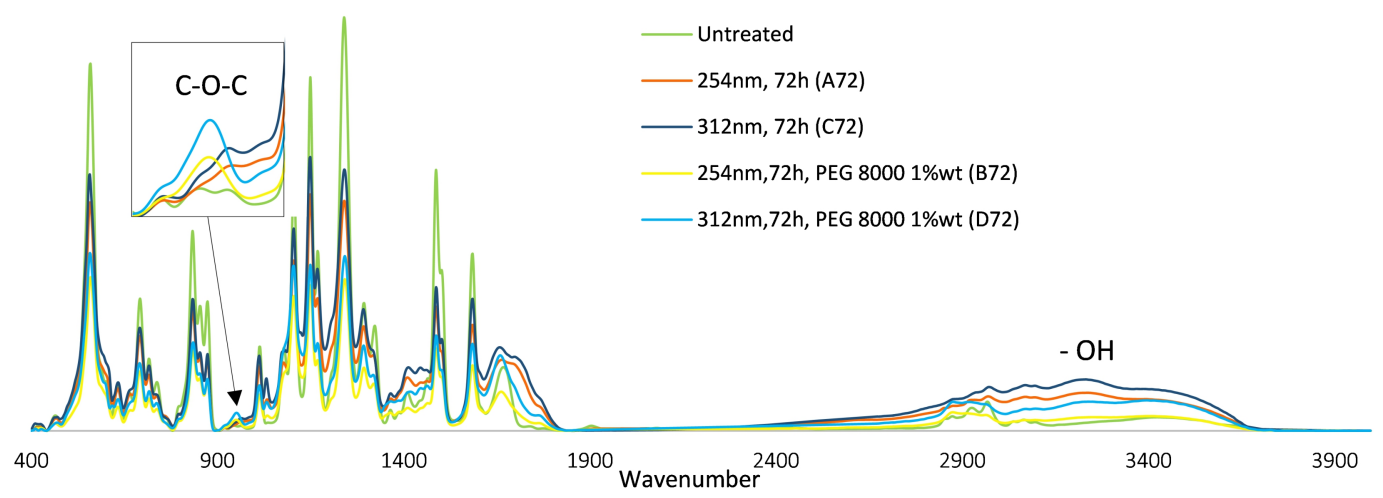

Figure 3 The FTIR spectra of membranes treated for 72 h with UV254 or UV312, with or without grafted

Furthermore, the membrane surface energies matched the WCA results. After UV treatment for $72 \mathrm{~h}$, the SE with UV254 and UV312 treatments had increased from $27.7 \mathrm{~mJ} / \mathrm{m}^{2}$ for untreated membrane to 68.2 and $59.9 \mathrm{~mJ} / \mathrm{m}^{2}$, respectively. In addition, the surface energy consists of a dispersive component that represents non-polar forces between non-polar molecules and of a polar component related to the bonding forces between polar molecules. An increased polar component for the treated membrane can indicate improved membrane surface wettability $[22,23]$.

After UV treatment for $72 \mathrm{~h}$, the polar component of the membrane surface increased from $4.1 \mathrm{~mJ} / \mathrm{m}^{2}$ for untreated to $49.1 \mathrm{~mJ} / \mathrm{m}^{2}$ and 56.6 $\mathrm{mJ} / \mathrm{m}^{2}$ for UV254 and UV312 treated membranes, respectively, shown in Figure 2B. So, for a long treatment time of up to $72 \mathrm{~h}$, the hydrophilicity and surface energy of membranes treated with UV312 were better when treated with UV254. However, for short treatment times of less than $10 \mathrm{~h}$, the hydrophilicity and surface energy with UV254 were better than with UV312. The hydrophilicity of PSF membrane surface may come from the hydroxyl groups that were confirmed by FTIR, as shown in Figure 3. The intensity of the hydroxyl $(-\mathrm{OH})$ groups in FTIR results $\left(3,100-3,600 \mathrm{~cm}^{-1}\right)$ was higher after UV312 treatment (dark blue line) than after UV254 treatment (orange line). The high-energy UV254 radiation may have destroyed formed $-\mathrm{OH}$ groups after $10 \mathrm{~h}$ of treatment. So, the membrane treated by UV254 has less $\mathrm{OH}$ on membrane surfaces than the membrane treated by UV312. The amount of polar functional groups on membrane surfaces contributed to hydrophilicity $[1,24]$. So, the PSF membrane that was treated for $72 \mathrm{~h}$ with UV312 had the lowest WCA and the highest SE, and this matches the results from FTIR.

Although WCA of the treated membrane surface strongly decreased after treatment with UV, the WCA of so treated membrane gradually increased in a few hours, in other words the hydrophilicity of the membrane decreased. The membrane was reverting back to hydrophobic after the UV treatment. This behavior may be caused by the decay of free radicals or of free charges on the membrane surfaces, leading to a rearrangement of

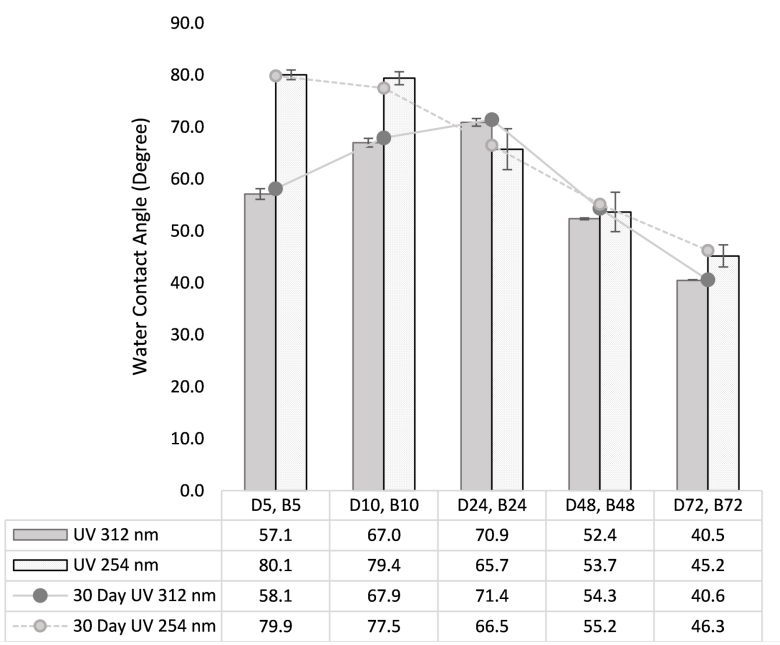

Figure 4 The water contact angles immediately after of PEG-UV treatment (bars) and 30 days later (lines)

the polar groups into the bulk material, or of nanpolar groups from the bulk to the surface, and migration of low molecular-weight oxidized materials (LMWOMs) from the surface to the bulk $[25,27]$. The rapid return of the membrane surface to hydrophobic status becomes an important issue that devalues the UVtreatment. However, this drawback can be solved by PEG-grafting. PEG was grafted on an active membrane surface after the UV irradiation treatment (PEG-UV). The results in Figure 4 show that as treatment time was increased, the WCA of the treated membrane (PEG-UV) decreased. For PEGUV254 (B5, B10, B24, B48, and B72) cases the WCA continued to decrease with treatment time, while for PEG-UV312 (D5, D10, D24, D48 and D72) cases the WCA pattern was different. With treatment times from 5 to $24 \mathrm{~h}$ (D5, D10, D24), the WCA increased, but with treatment times longer than 24 hours (D48, D72) the WCA decreased. This behavior may be caused by the broad wavelength spread of the UV light, as shown in Figure 1B. Although UV-254 provided lower WCA than UV-312 for treatment in a short period (less than $10 \mathrm{~h}$ ), but for long period of treatment time (more than $10 \mathrm{~h}$ ) UV-312 provided lower WCA than 
UV-254. These results may cause by the prominent intensity of UV source. UV-254 has only one prominent peak while UV-312 has two prominent peaks $(312 \mathrm{~nm}$ and $360-370 \mathrm{~nm}$ ) which shown the better results than UV-254 after treatment for more than $10 \mathrm{~h}$ shown in Figure 4.

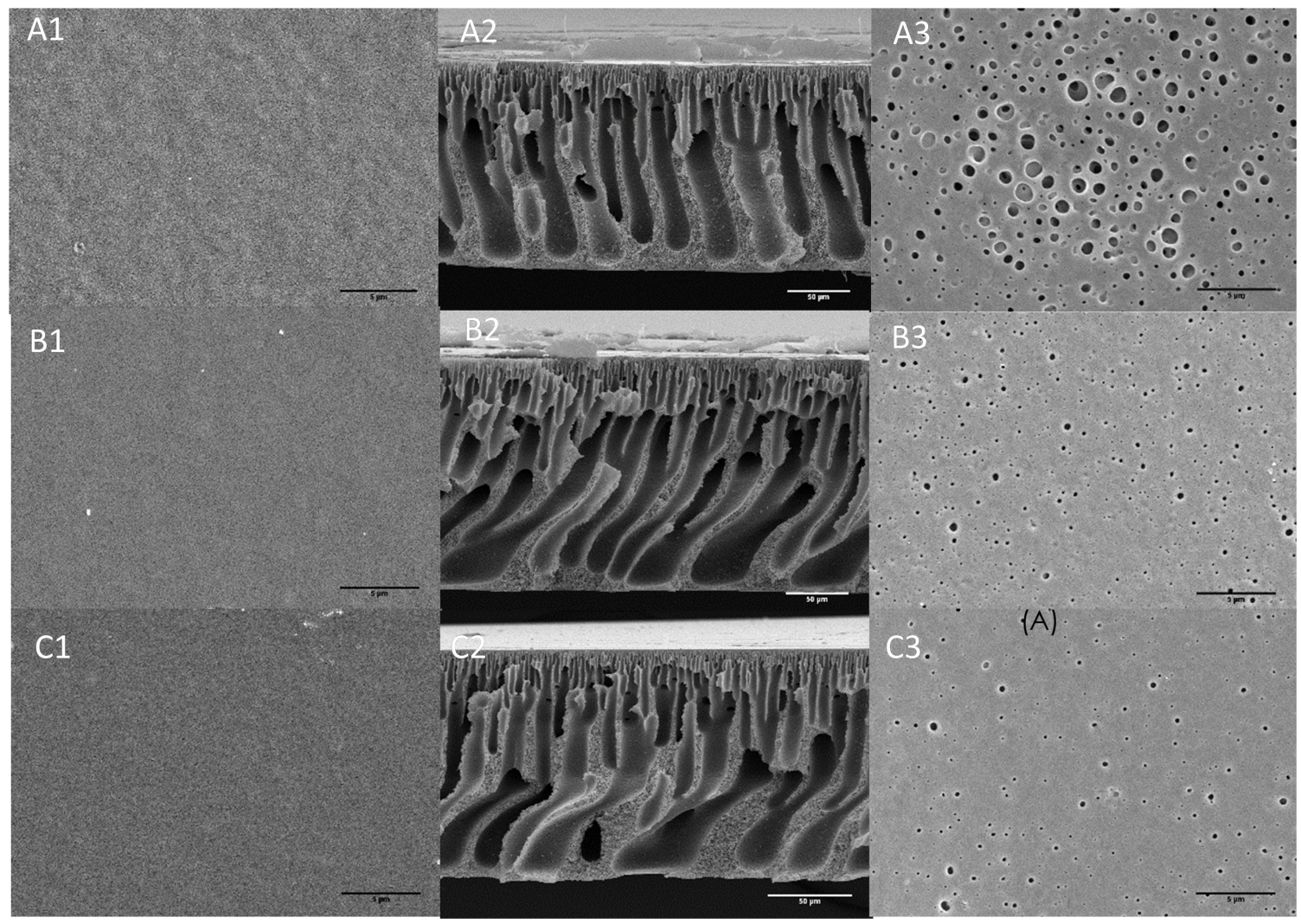

Figure 5 SEM images $A 1, B 1$, and $C 1$ are of the top; $A 2, B 2$, and $C 2$ of the cross section; and $A 3$, B3, and $C 3$ of the bottom of the membrane. Here A, B, and C are the D5, D24 and D72 conditions, respectively

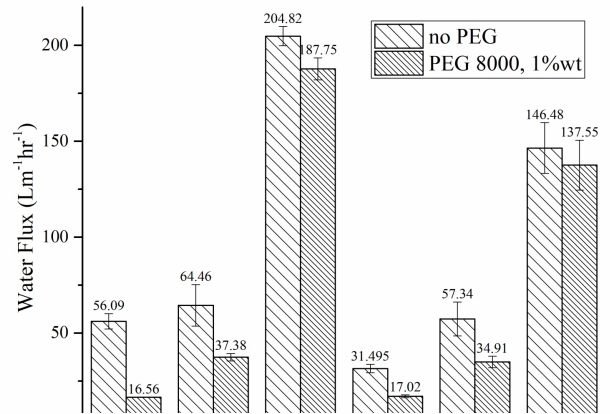

(A)

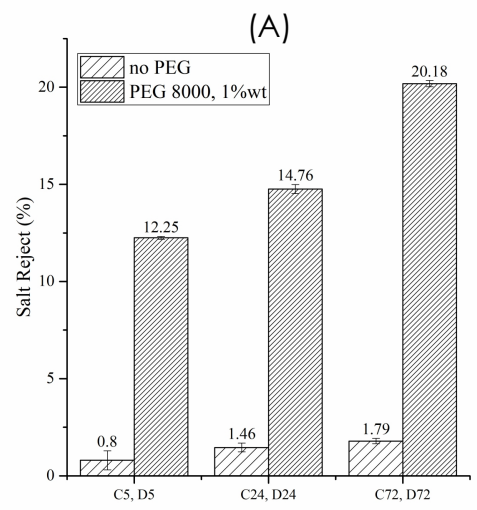

(B)

However, both UV $254 \mathrm{~nm}$ and UV $312 \mathrm{~nm}$ treatments gave the lowest WCA with $72 \mathrm{~h}$ treatment, and PEG-UV312 (D72) case had a lower WCA than the PEG-UV254 (B72) case. Furthermore, the WCA of each treated membrane remained constant after 30 days from the completed membrane treatment. This means that PEG-UV combination can provide prolonged hydrophilicity to treated membranes, for at least 30 days after completion of the treatment. The PEGUV312 approach uses high energy from UV light to cut hydrogen bonding ( $\mathrm{H}-)$ from methyl side groups in the PSF membrane and reconstructs chemical bonds by grafting with PEG. On the other hand, the excess energy of UV $254 \mathrm{~nm}$ irradiation can destroy the structure of membrane surface, causing pore etching or polymer chain scission(Bin the membrane [28, 29]. So, PEG grafting after UV $312 \mathrm{~nm}$ treatment was better than after UV $254 \mathrm{~nm}$ treatment. The FTIR spectra in Figure 3 show the $\mathrm{C}-\mathrm{O}-\mathrm{C}$ ether stretch peaks $[1,30,31]$ at $1,100-1,300 \mathrm{~cm}^{-1}$, and intensity of the light blue line (PEG-UV312 treatment, D72) is higher than that of the yellow line (PEG-UV254 treatment, B72). The intensity of $\mathrm{C}-\mathrm{O}-\mathrm{C}$ relates to the PEG functional groups. This means that the intensity of $\mathrm{C}-\mathrm{O}-\mathrm{C}$ can indicate the amount of

Figure 6 Water flux (A), and salt rejection (B) of PEGUV treated membranes 
PEG on PSF membrane surface. The results in Figure 4 reveal that WCA after PEG-UV312 treatment was lower than after PEG-UV254 treatment, matching the FTIR results in Figure 3.

The morphologies of PEG-UV312 treated membranes after treatments for $5 \mathrm{~h}, 24 \mathrm{~h}$ and $72 \mathrm{~h}$ (D5, D24, and D72) are shown in Figure 5. These show small pores on membrane surfaces due to the PEG adhered on the polymer component, and show similar morphologies for both top surface $(A 1, B 1$, and $C 1)$ and cross-section (A2, B2, and C2).

Although the pores are small, the water flux and salt rejection results improved with treatment time, as shown in Figure 6. This may be caused by improved hydrophilicity of the treated membrane surfaces, due to PEG grafting.

\subsection{CONCLUSION}

Hydrophilicity of a PSF membrane can be improved by UV irradiation, which can beneficially be followed by PEG grafting. The energy of UV light can break down chemical bonds on the PSF polymer membrane, so that polar functional groups are created on the membrane surface. Different UV wavelengths provide different photon energy levels, which affects the mechanisms and reactions on the membrane surfaces, leading to different surface wettability responses to treatment time. In addition, PEG grafting after the UV treatment was found to prolong hydrophilicity to last for at least 30 days after treatment. Furthermore, membrane improved by PEG-UV treatment provided high permeability and selectivity at the same time, which is attributed to the polar functional groups of PEG on the treated membrane surfaces.

\section{Acknowledgement}

Financial support from the Science Achievement Scholarship of Thailand is acknowledged. The authors would like to thank to the Center of Excellence in Membrane science and technology (CoE-MST), Center of Excellence in Nanotechnology for Energy (CENE) and Division of Physical Science, Faculty of Science, PSU, for providing the facilities needed.

\section{References}

[1] Chittrakarn, T., Y. Tirawanichakul, S. Sirijarukul, and C. Yuenyao. 2016. Plasma Induced Graft Polymerization of Hydrophilic Monomers on Polysulfone Gas Separation Membrane Surfaces. Surface and Coatings Technology. 296: 157-163.

DOI: https://doi.org/10.1016/j.surfcoat.2016.04.018

[2] Kim, I. C., and K. H. Lee. 2003. Effect of Various Additives on Pore Size of Polysulfone Membrane by Phase-inversion Process. Journal of Applied Polymer Science. 89(9): 25622566.

DOI: https://doi.org/10.1002/app.12009.
[3] Kim, K. S., K. H. Lee, K. Cho, and C. K. Park. 2002. Surface Modification of Polysulfone Ultrafiltration Membrane by Oxygen Plasma Treatment. Journal of Membrane Science. 199(1): 135-145.

DOI: https://doi.org/10.1016/\$0376-7388/01)00686-X.

[4] Rahimpour, A. 2011. UV Photo-grafting of Hydrophilic Monomers onto the Surface of Nano-porous PES Membranes for improving Surface Properties. Desalination. 265(1-3): 93-101.

DOI: https://doi.org/10.1016/j.desal.2010.07.037.

[5] Zhao, W., Y. Su, C. Li, Q. Shi, X. Ning, and Z. Jiang. 2008. Fabrication of Antifouling Polyethersulfone Ultrafiltration Membranes using Pluronic F127 as both Surface Modifier and Pore-forming Agent. Journal of Membrane Science. 318(1-2): 405-412.

DOl: https://doi.org/10.1016/j.memsci.2008.03.013.

[6] Nyström, M., and P. Järvinen. 1991. Modification of Polysulfone Ultrafiltration Membranes with UV Irradiation and Hydrophilicity Increasing Agents. Journal of Membrane Science. 60(2-3): 275-296.

DOI: https://doi.org/10.1016/S0376-7388(00)81540-9.

[7] Rana, D., T. Matsuura, R. M. Narbaitz, and C. Feng. 2005. Development and Characterization of Novel Hydrophilic Surface Modifying Macromolecule for Polymeric Membranes. Journal of Membrane Science. 249(1-2): 103112

DOl: https://doi.org/10.1016/j.memsci.2004.09.034.

[8] Genné, I., S. Kuypers, and R. Leysen. 1996. Effect of the Addition of $\mathrm{ZrO}_{2}$ to Polysulfone based UF Membranes. Journal of Membrane Science. 113(2): 343-350. DOI: https://doi.org/10.1016/0376-7388(95)00132-8.

[9] Wu, J., W. Wei, S. Li, Q. Zhong, F. Liu, J. Zheng, and J. Wang. 2018. The Effect Of Membrane Surface Charges On Demulsification and Fouling Resistance during Emulsion Separation. Journal of Membrane Science. 563: 126-133. DOI: https://doi.org/10.1016/j.memsci.2018.05.065.

[10] Yuenyao, C., Y. Tirawanichakul, and T. Chittrakarn. 2015. Asymmetric Polysulfone Gas Separation Membranes Treated by Low Pressure DC Glow Discharge Plasmas. Journal of Applied Polymer Science. 132(24): 1-10. DOI: https://doi.org/10.1002/app.42116.

[11] Xi, Z.Y., Y.Y. Xu, L.P. Zhu, and B.K. Zhu. 2009. Modification of Polytetrafluoroethylene Porous Membranes by Electron Beam Initiated Surface Grafting of Binary Monomers. Journal of Membrane Science. 339(1-2): 33-38. DOl: https://doi.org/10.1016/j.memsci.2009.04.025.

[12] Qiu, J., Y. Zhang, Y. Shen, Y. Zhang, H. Zhang, and J. Liu. 2010. Hydrophilic Modification of Microporous Polysulfone Membrane Via Surface-initiated Atom Transfer Radical Polymerization of Acrylamide. Applied Surface Science. 256(10): 3274-3280. DOI: https://doi.org/10.1016/j.apsusc.2009.12.018.

[13] Homayoonfal, M., A. Akbari, and M. R. Mehrnia. 2010. Preparation of Polysulfone Nanofiltration Membranes by UVAssisted Grafting Polymerization for Water Softening. Desalination. 263(1-3): 217-225. DOI: https://doi.org/10.1016/j.desal.2010.06.062.

[14] Kaeselev, B., P. Kingshott, and G. Jonsson. 2002. Influence of the Surface Structure on the Filtration Performance of UVmodified PES Membranes. Desalination. 146(1-3): 265-271. DOI: https://doi.org/10.1016/S0011-9164(02)00485-X.

[15] Abuhabib, A. A., A. W. Mohammad, N. Hilal, R. A. Rahman, and A. H. Shafie. 2012. Nanofiltration Membrane Modification by UV Grafting for Salt Rejection and Fouling Resistance Improvement for Brackish Water Desalination. Desalination. 295: 16-25. DOI: https://doi.org/10.1016/j.desal.2012.03.020.

[16] Tajau, R., M. I. Ibrahim, N. M. Yunus, M. H. Mahmood, M. Z. Salleh, and N. G. N. Salleh. 2014. Development of Palm OilBased UV-Curable Epoxy Acrylate and Urethane Acrylate Resins for Wood Coating Application. Advancing Nuclear Research and Energy Development. 1584: 164-169. DOI: https://doi.org/10.1063/1.4866125. 
[17] Tamulaitis, G. 2011. Ultraviolet Light Emitting Diodes. Lithuanian Journal of Physics. 51 (3): 177-192. DOI: https://doi.org/10.3952/lithjphys.51307.

[18] Sirijarukul, S. 2007. Elaboration de membranes a traces en poly(ethyleneterephtalate) ayant un gradient lineaire de taille de pore et une porosite constante. PhD. Thesis. Universite Montpellier2, Montperllier.

[19] Pandiyaraj, K. N., J. Heeg, A. Lampka, F. Junge, T. Barfels, M. Wienecke, Y. H. Rhee, and H. W. Kim. 2012. In Vitro Cyto and Blood Compatibility of Titanium Containing Diamond-like Carbon Prepared by Hybrid Sputtering Method. Plasma Science and Technology. 14(9): 829-836. DOI: https://doi.org/10.1088/1009-0630/14/9/11.

[20] Papadakis, V. G. 1969. Estimation of the Surface Free Energy of Polymers. Journal of Applied Polymer Science. 13: 17411747.

[21] Sirinupong, T., W. Youravong, D. Tirawat, W. J. Lau, G. S. Lai, and A. F. Ismail. 2018. Synthesis and Characterization of Thin Film Composite Membranes Made of PSF-TiO $/$ GO Nanocomposite Substrate for Forward Osmosis Applications. Arabian Journal of Chemistry. 11 (7): 1144-1153. DOI: https://doi.org/10.1016/j.arabjc.2017.05.006.

[22] Juang, R. S., W. T. Hou, Y. C. Huang, Y. C. Tseng, and C. Huang. 2016. Surface Hydrophilic Modifications on Polypropylene Membranes by Remote Methane/Oxygen Mixture Plasma Discharges. Journal of the Taiwan Institute of Chemical Engineers. 65: 420-426. DOI: https://doi.org/10.1016/j.jice.2016.04.032.

[23] Wang, B., Y. Zhang, L. Shi, J. Li, and Z. Guo. 2012. Advances in the Theory of Superhydrophobic Surfaces. Journal of Materials Chemistry. 22(38): 20112-20127. DOI: https://doi.org/10.1039/c2jm32780e.

[24] Konruang, S., S. Sirijarukul, P. Wanichapichart, L. YU, and T. Chittrakarn. 2015. Ultraviolet-ray Treatment of Polysulfone Membranes on the $\mathrm{O}_{2} / \mathrm{N}_{2}$ and $\mathrm{CO}_{2} / \mathrm{CH}_{4}$ Separation Performance. Journal of Applied Polymer Science. 132(25): 4-11. DOI: https://doi.org/10.1002/app.42074.

[25] Lawton, R. A., C. R. Price, A. F. Runge, W. J. Doherty, and S. S. Saavedra. 2005. Air Plasma Treatment of Submicron Thick
PDMS Polymer Films: Effect of Oxidation Time and Storage Conditions. Physicochemical and Engineering Aspects. 253(1-3): 213-215.

DOI: https://doi.org/10.1016/j.colsurfa.2004.11.010.

[26] Garcia, D., O. Fenollar, R. Lopez, and R. Balart. 2008. Durability of the Wettability Properties of a Polypropylene Film with a Low-Pressure $\mathrm{CH}_{4}-\mathrm{O}_{2}$ Plasma Treatment. Journal of Applied Polymer Science. 110: 1201-1207. DOI: https://doi.org/10.1002/app.

[27] Waddell, E. A., S. Shreeves, H. Carrell, C. Perry, B. A. Reid, and J. McKee. 2008. Surface Modification of Sylgard 184 Polydimethylsiloxane by $254 \mathrm{~nm}$ Excimer Radiation and Characterization by Contact Angle Goniometry, Infrared Spectroscopy, Atomic Force and Scanning Electron Microscopy. Applied Surface Science. 254(17): 5314-5318. DOI: https://doi.org/10.1016/j.apsusc.2008.02.087.

[28] YU, H., Y. Cao, G. Kang, J. Liu, M. Li, and Q. Yuan. 2009. Enhancing Antifouling Property of Polysulfone Ultrafiltration Membrane by Grafting Zwitterionic Copolymer via UVinitiated Polymerization. Journal of Membrane Science. 342(1-2): 6-13. DOI: https://doi.org/10.1016/j.memsci.2009.05.041.

[29] Ulbricht, M., M. Riedel, and U. Marx. 1996. Novel Photochemical Surface Functionalization of Polysulfone Ultrafiltration Membranes for Covalent Immobilization of Biomolecules. Journal of Membrane Science. 120(2): 239259.

DOI: https://doi.org/10.1016/0376-7388(96)00148-2.

[30] Alcantar, N. A., E. S. Aydil, and J. N. Israelachvili. 2000. Polyethylene Glycol-coated Biocompatible Surfaces. Journal of Biomedical Materials Research. 51 (3): 343-351. DOl: https://doi.org/10.1002/1097-4636(20000905)51:3<343:: AID-JBM7>3.0.CO;2-D.

[31] Woo, S. M., D. J. Kim, and S. Y. Nam. 2014. Preparation and Properties of Polysulfone-poly(ethylene glycol) Graft Copolymer Membrane. Journal of Nanoscience and Nanotechnology. 14(10): 7804-7808.

DOI: https://doi.org/10.1166/jnn.2014.9468. 